\title{
Regional Gray Matter Growth, Sexual Dimorphism, and Cerebral Asymmetry in the Neonatal Brain
}

\author{
John H. Gilmore, ${ }^{1,2}$ Weili Lin, ${ }^{3}$ Marcel W. Prastawa, ${ }^{4}$ Christopher B. Looney, ${ }^{3}$ Y. Sampath K. Vetsa, ${ }^{4}$ \\ Rebecca C. Knickmeyer, ${ }^{1,2}$ Dianne D. Evans, ${ }^{1,2}$ J. Keith Smith, ${ }^{3}$ Robert M. Hamer, ${ }^{1,2,5}$ Jeffrey A. Lieberman, ${ }^{6}$ and \\ Guido Gerig ${ }^{1,2,4}$ \\ ${ }^{1}$ UNC Schizophrenia Research Center and Departments of ${ }^{2}$ Psychiatry, ${ }^{3}$ Radiology, ${ }^{4}$ Computer Science, and ${ }^{5}$ Biostatistics, University of North Carolina at

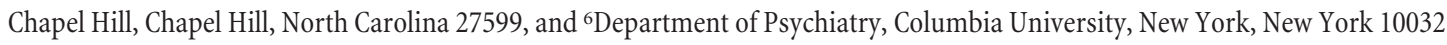

\begin{abstract}
Although there has been recent interest in the study of childhood and adolescent brain development, very little is known about normal brain development in the first few months of life. In older children, there are regional differences in cortical gray matter development, whereas cortical gray and white matter growth after birth has not been studied to a great extent. The adult human brain is also characterized by cerebral asymmetries and sexual dimorphisms, although very little is known about how these asymmetries and dimorphisms develop. We used magnetic resonance imaging and an automatic segmentation methodology to study brain structure in 74 neonates in the first few weeks after birth. We found robust cortical gray matter growth compared with white matter growth, with occipital regions growing much faster than prefrontal regions. Sexual dimorphism is present at birth, with males having larger total brain cortical gray and white matter volumes than females. In contrast to adults and older children, the left hemisphere is larger than the right hemisphere, and the normal pattern of fronto-occipital asymmetry described in older children and adults is not present. Regional differences in cortical gray matter growth are likely related to differential maturation of sensory and motor systems compared with prefrontal executive function after birth. These findings also indicate that whereas some adult patterns of sexual dimorphism and cerebral asymmetries are present at birth, others develop after birth.
\end{abstract}

Key words: human; magnetic resonance imaging; brain development; cortex; white matter; myelination

\section{Introduction}

The first year of life is perhaps the most dynamic phase of postnatal brain development, with rapid development of a wide range of cognitive and motor functions (Kagen and Herschkowitz, 2005). Although there has been a great deal of recent interest in the study of childhood and adolescent brain development, very little is known about normal brain development in the first few months of life. Previous magnetic resonance imaging (MRI) studies of a small number of healthy neonates being compared with prematurely born infants found gray and white matter volumes increased in the perinatal period (Huppi et al., 1998; Peterson et al., 2003); in a recent preliminary study, white matter growth appeared to slow after the 36 week gestational age (Nishida et al., 2006).

Cross-sectional neuroimaging studies of older children indicate that cortical gray matter volumes decrease after $4-5$ years of age to puberty (Pfefferbaum et al., 1994; Reiss et al., 1996; Courchesne et al., 2000; De Bellis et al., 2001). A longitudinal

Received Aug. 2, 2006; revised Dec. 1, 2006; accepted Jan. 2, 2007.

This work was supported by University of North Carolina Conte Center Grants MH064065 (J.H.G., J.A.L.), HD03110 (G.G.), and HD40127 (R.C.K.).We thank Kathy Wilber for her technical assistance and Chaeryon Kang for her assistance with data analysis.

Correspondence should be addressed to Dr. John H. Gilmore, Department of Psychiatry, Campus Box 7160, University of North Carolina at Chapel Hill, Chapel Hill, NC27599-7160. E-mail: jgilmore@med.unc.edu. DOI:10.1523/JNEUROSCI.3339-06.2007

Copyright $\odot 2007$ Society for Neuroscience $\quad$ 0270-6474/07/271255-06\$15.00/0 study found regional differences in cortical gray matter development (Giedd et al., 1999). White matter volumes increase throughout later childhood and adolescent brain development (Pfefferbaum et al., 1994; Caviness et al., 1996; Giedd et al., 1999).

Sexual dimorphisms are present in the adult brain, with males having larger total brain volumes (Gur et al., 1999; Nopoulos et al., 2000; Goldstein et al., 2001). Older male children also have larger overall brain volumes and gray and white matter volumes than females (Caviness et al., 1996; Giedd et al., 1996; Reiss et al., 1996).

Structural asymmetries of the human brain appear to underlie functional asymmetries, including language and handedness (Toga and Thompson, 2003). Cerebral asymmetries in the adult brain include the right hemisphere being larger than the left hemisphere, accounted for mainly by more white matter on the right, and fronto-occipital asymmetry or torque, in which the right prefrontal cortex is larger than the left, whereas the left occipital cortex is larger than the right (Nopoulos et al., 2000; Good et al., 2001; Toga and Thompson, 2003; Raz et al., 2004). Adult patterns of cerebral asymmetry have been observed in older children (Caviness et al., 1996; Giedd et al., 1996; Reiss et al., 1996; Matsuzawa et al., 2001; Herbert et al., 2005).

Abnormalities of cortical gray and white matter have been described in neurodevelopmental disorders including schizophrenia (Honea et al., 2005) and autism (Hazlett et al., 2005). Similarly, abnormalities of normal cerebral asymmetries and 
gender differences have been observed in schizophrenia (Bilder et al., 1994; Sommer et al., 2001; Goldstein et al., 2002), autism (Herbert et al., 2005; Rojas et al., 2005), Tourette syndrome (Hong et al., 2002), and developmental stuttering (Foundas et al., 2003). A better understanding of normal cortical gray and white matter development in the early postnatal period, as well as how and when normal cerebral asymmetries and sexual dimorphisms develop, would provide important insights into these neurodevelopmental disorders. We present a study of regional cortical growth, sexual dimorphism, and cerebral asymmetry in a large cohort of healthy neonates.

\section{Materials and Methods}

Subjects. This study was approved by the Institutional Review Board of the University of North Carolina (UNC) School of Medicine. Infants scanned for this study were part of a larger study of prenatal and neonatal brain development in children at high risk for neurodevelopmental disorders and controls. Control mothers were recruited during the second trimester of pregnancy from the outpatient obstetrics and gynecology clinics at UNC hospitals. Exclusion criteria were the presence of abnormalities on fetal ultrasound or major medical or psychotic illness in the mother. Singleton subjects with a gestational age $\geq 37$ weeks who had both $\mathrm{T} 1$ and $\mathrm{T} 2$ /proton density scans that were free of major motion were included in this analysis $(n=78)$. All scans were reviewed by a neuroradiologist (J.K.S.). Additional exclusion criteria for this analysis included major delivery, neonatal complications, or significant CNS abnormality on MRI $(n=4)$. Twelve subjects had small incidental subdural hematomas or other intracranial bleeds, which are present in $\sim 25 \%$ of vaginal births (Looney et al., 2007); these subjects were included in the analysis.

Image acquisition. Neonates were scanned without being sedated, fed before scanning, swaddled, fitted with ear protection, and had their heads secured in a vacuum-fixation device. A physician or nurse was present during each scan; a pulse oximeter was used to monitor heart rate and oxygen saturation. T1-weighted structural pulse sequences were a threedimensional (3D) magnetization prepared rapid gradient echo [repetition time (TR), $1820 \mathrm{~ms}$; inversion time (TI), $400 \mathrm{~ms}$; echo time (TE), $4.38 \mathrm{~ms}$; flip angle $7^{\circ}$ ] in the early phases of the study $(n=9)$ and a 3D T1-weighted fast low-angle shot (TR, $15 \mathrm{~ms}$; TE, $7 \mathrm{~ms}$; flip angle, $25^{\circ} ; n=$ 65). Proton density and T2-weighted images were obtained with a turbo spin echo sequence (TR, $6200 \mathrm{~ms}$; TE1, $20 \mathrm{~ms}$; TE2, $119 \mathrm{~ms}$; flip angle, $\left.150^{\circ}\right)$. The spatial resolution was a $1 \times 1 \times 1 \mathrm{~mm}$ voxel for T1-weighted images and a $1.25 \times 1.25 \times 1.5 \mathrm{~mm}$ voxel with a $0.5 \mathrm{~mm}$ interslice gap for proton density and T2-weighted images.

The Siemens (Malvern, PA) head-only 3T scanner is Food and Drug Administration approved for use in all age groups. Specific absorption rates are kept within safe levels for body weight by both hardware and software features of the scanner. We have previously confirmed that the scan sequences did not cause significant temperature increases with a phantom (Gilmore et al., 2004).

Image analysis. Our segmentation method (Prastawa et al., 2005) is an extension of a previously developed atlas-moderated automatic tissue classification technique that uses an iterative expectation maximization segmentation (EMS) algorithm (Wells et al., 1996; Van Leemput et al., 1999; Prastawa et al., 2005). The method operates on single- or multichannel MRI data and uses a coregistered probabilistic brain atlas as a spatial prior. The EMS tool incorporates multi-channel image registra- tion, registration of the probabilistic brain atlas to the subject, automatic bias inhomogeneity correction, and brain stripping in one integrated framework, which offers significant advantages over processing pipelines in which each of the tasks is solved as a separate, independent processing step. In neonate MRI, the low contrast-to-noise ratio of nonmyelinated white matter to cortical and subcortical gray matter required significant changes. Parametric modeling of multivariate distributions is replaced by robust graph clustering and parameter estimation, resulting in an intermediate segmentation. This segmentation is finally refined using training sample pruning and nonparametric kernel density estimation. The segmentation of a two-channel MRI of the neonate brain is depicted in Figure 1. A validation study of the automatic segmentation showed very good agreement with human-expert segmentation (Prastawa et al., 2005). The segmentation process is fully automatic, takes $\sim 30 \mathrm{~min}$ on a standard personal computer workstation, and does not require human interaction, which often limits reliability. EMS requires a probabilistic brain atlas to define local geometric priors for each tissue category, but existing probabilistic atlases for adults are not appropriate for pediatric studies. We followed the concept proposed by Evans et al. (1993) to build a new statistical brain atlas for the neonatal age group.

Parcellation of each subject's brain into regions is achieved by nonlinear warping of a parcellation atlas template (Rueckert et al., 1999). The brain atlas template MRI, subdivided into regions by anatomical experts, serves as the template (Fig. 1). Left and right hemispheres were subdivided into four regions along the anteroposterior axis (prefrontal, frontal, parietal, occipital) and into infratentorial and supratentorial regions. The cerebellum, brainstem, and combined sets of subcortical structures are represented separately. This parcellation template is registered to each individual subject's MRI by volumetric nonlinear-by-nonlinear deformation based on mutual information criterion (Rueckert et al., 1999), combined with the individual tissue segmentation masks, and results in an estimate of gray, white, and CSF volume for each region along the anteroposterior axis.

Statistical analysis. For cross-sectional analyses of gender differences on volumes, a two-group one-way ANOVA was used, with intracranial volume (ICV) added as a covariate. For examinations of cerebral asymmetry, we used paired $t$ tests of right-left volumes without covariates, 


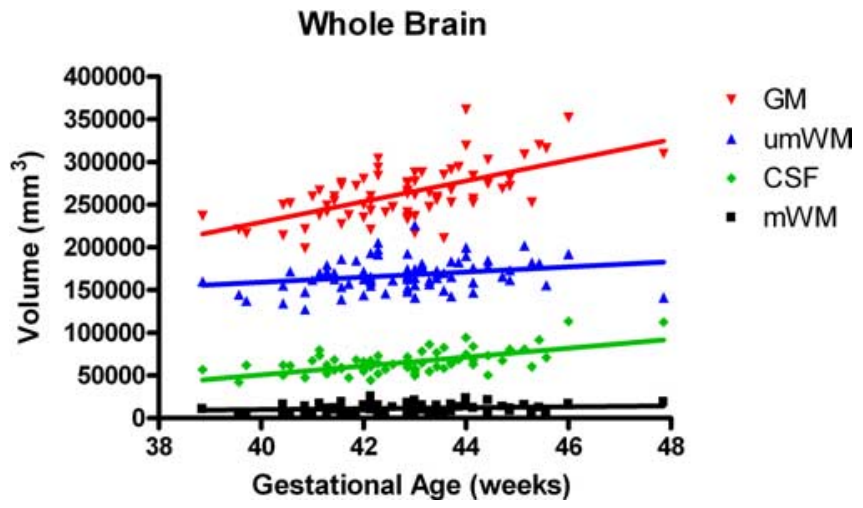

Figure 2. Tissue-specific growth rates in whole brain $(n=74)$. There is a significant overall difference in slopes (inhomogeneity of slopes: $F_{(3,288)}=16.6 ; p<0.0001$ ). There are significant differences in growth rates between gray matter (GM) and unmyelinated white matter (umWM) $\left(F_{(1,288)}=28.0 ; p<0.0001\right)$ and between $G M$ and myelinated white matter $(\mathrm{mWM})$ $\left(F_{(1,288)}=44.9 ; p<0.0001\right)$.

because these were entirely within-subject comparisons; analysis was repeated separately for each gender. For growth trajectory models, we fit mixed models with prefrontal, frontal, parietal, and occipital regions (each overall region combines left and right inferior and superior subregions determined by the parcellation template) as the within-subject variable of interest and age at MRI as a continuous predictor. In this model, we examined differences in slopes between regions with contrasts.

\section{Results}

The final study sample $(n=74)$ included 40 males and 34 females; the ethnic composition was 61 Caucasians, 12 African Americans, and 1 Asian American. The gestational age at MRI was $42.8 \pm 1.6$ weeks (mean $\pm \mathrm{SD}$; range, 38.8-47.8 weeks). There were no significant gender differences in the gestational age at birth (male, $39.7 \pm 0.9$ weeks; female, $39.6 \pm 1.0$ weeks; $p=$ 0.79 ) or the gestational age at MRI (male, $43.0 \pm 1.7$ weeks; female, $42.6 \pm 1.5$ weeks; $p=0.28$ ). There was a significant difference in birth weight between males and females (male, $3587.7 \pm 465.5 \mathrm{~g}$; female, $3278.7 \pm 407.39 \mathrm{~g} ; p=0.0036)$.

In the first several weeks after birth, total gray matter grew robustly compared with myelinated and unmyelinated white matter (inhomogeneity of slopes: $F_{(3,288)}=16.6 ; p<0.0001$ ) (Fig. 2). In the cortex, overall trajectories of gray matter growth were similar in males and females, although there was a trend for female cortical unmyelinated white matter growth to be more rapid than for males $\left(F_{(1,70)}=3.2 ; p=0.08\right)$. Interestingly, there is a posterior to anterior gradient for cortical gray matter development. There were significant differences in the regional growth rates, with the occipital and parietal regions growing significantly faster than the prefrontal region $\left(F_{(3,288)}=8.61 ; p<0.0001\right)$ (Fig. $3)$. This overall posterior-greater than-anterior regional growth was also seen in the unmyelinated white matter compartment, although it was less pronounced compared with gray matter and not statistically significant $\left(F_{(3,288)}=1.5 ; p=0.218\right)$ (Fig. 4).

We found that sexual dimorphism was present in the early postnatal brain (Table 1), with males having ICVs $7.8 \%$ larger than females (two-group one-way ANOVA; $F_{(1,72)}=10.0$; $p=0.0023$ ), comparable to the gender difference in birth weight of $9.42 \%$. Males had significantly larger ICVs compared with females, even controlling for birth weight $\left(F_{(1,71)}=4.3\right.$; $p=0.0418)$. Males had $\sim 10.2 \%$ more cortical gray matter $\left(F_{(1,72)}=\right.$ $11.35 ; p=0.0012)$ and $6.4 \%$ more cortical white matter $\left(F_{(1,72)}=\right.$ $6.0 ; p=0.0169)$ than females. Males also had $7.8 \%$ larger subcortical gray matter volumes $\left(F_{(1,72)}=4.28 ; p=0.0423\right)$ than fe-

\section{Cortical Gray Matter}

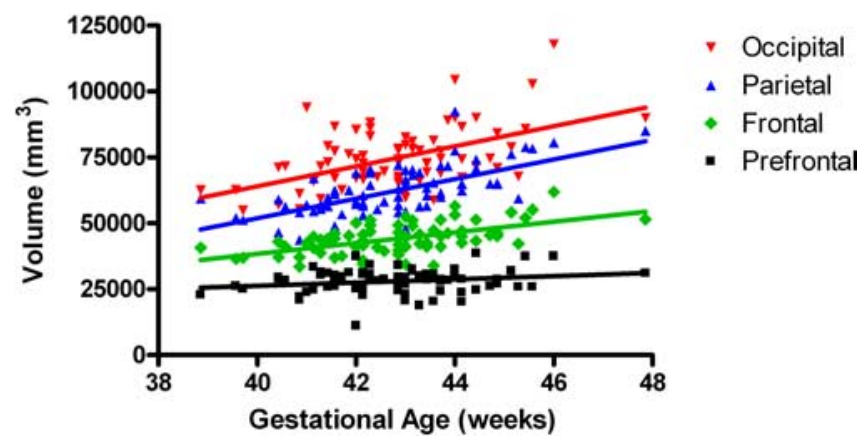

Figure 3. Regional growth of cortical gray matter $(n=74)$. There is a significant overall regional difference in slopes (inhomogeneity of slopes: $F_{(3,288)}=8.6 ; p<0.0001$ ). There were significant differences between occipital and prefrontal $\left(F_{(1,288)}=18.9 ; p<0.0001\right)$, occipital and frontal $\left(F_{(1,288)}=5.8 ; p=0.0166\right)$, and parietal and prefrontal $\left(F_{(1,288)}=17.9 ; p<\right.$ $0.0001)$ matter growth rates.

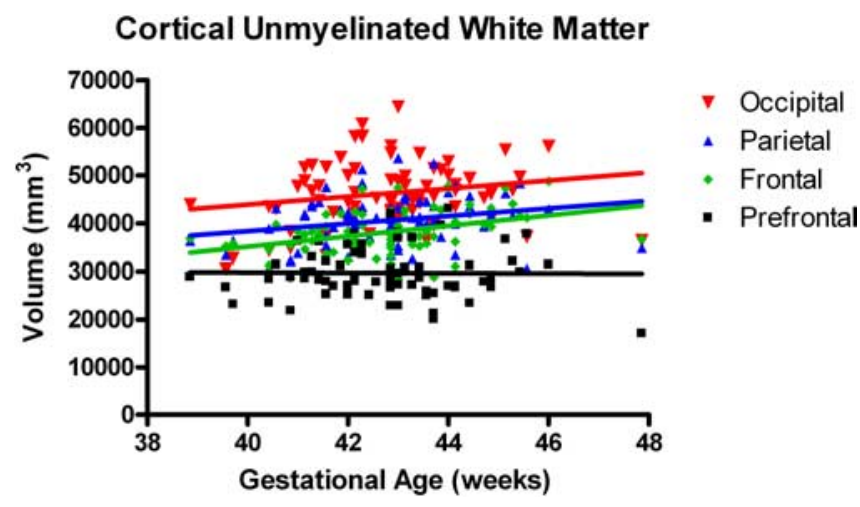

Figure 4. Regional growth of cortical unmyelinated white matter $(n=74)$. There was not a significant regional difference in slopes for unmyelinated white matter (inhomogeneity of slopes: $\left.F_{(3,288)}=1.5 ; p=0.2180\right)$.

males. These differences were related to the ICV of males, because there were no significant gender differences when controlling for ICV (Table 3). There was no significant gender difference in lateral ventricle or cerebellum volume in the first weeks of life, although males tended to have larger volumes (Table 1).

Cerebral asymmetry was present at birth (Table 2), with the left hemisphere $\sim 4.3 \%$ larger than the right $\left(t_{(73)}=14.2 ; p<\right.$ 0.0001 ), which is the opposite of the right-greater than-left asymmetry observed in older children and adults. This left-greater than-right-hemisphere asymmetry was a very consistent finding, present in 70 subjects $(94.6 \%)$. Left-greater than-right asymmetry was present in hemispheric gray matter $\left(4.6 \% ; t_{(73)}=9.3 ; p<\right.$ $0.0001)$ and white matter $\left(1.2 \% ; t_{(73)}=2.8 ; p=0.0065\right)$, although more pronounced in gray matter compared with white matter. Left-greater than-right asymmetries of the subcortical gray matter $\left(6.8 \% ; t_{(73)}=11.4 ; p<0.0001\right)$ and lateral ventricles $\left(37.9 \% ; t_{(73)}=2.9 ; p=0.0054\right)$ are also evident in the early postnatal period. Males and females had similar patterns of asymmetry in total hemisphere volume, hemispheric gray matter, hemispheric white matter, subcortical gray matter, and lateral ventricles (data not shown).

We did not observe torque in the neonatal brain. Whereas the left occipital region was larger than the right, as expected $(10.4 \%$; $\left.t_{(73)}=18.8 ; p<0.0001\right)$, the left prefrontal region was actually nonsignificantly larger than the right $\left(0.92 \% ; t_{(73)}=-1.9 ; p=\right.$ 0.0603 ), which is the opposite pattern of that observed in adults 
Table 1. Sexual dimorphism

\begin{tabular}{lcccc}
\hline & Male, mean (SD) & Female, mean (SD) & Difference, M $>\mathrm{F}(\%)$ & $p$ value, ICV controlled \\
\hline Birth weight $(\mathrm{g})$ & $3587.7(465.5)$ & $3278.7(407.7)$ & 9.42 & 0.0036 \\
ICV $\left(\mathrm{mm}^{3}\right)$ & $525,524(58,637)$ & $487,378(41,848)$ & 7.83 & 0.0023 \\
Hem GM $\left(\mathrm{mm}^{3}\right)$ & $218,212(28,693)$ & $197,945(197,944)$ & 10.24 & 0.0012 \\
Hem umWM $\left(\mathrm{m}^{3}\right)$ & $163,987(18,420)$ & $154,146(15,745)$ & 6.38 & 0.0169 \\
Subcort GM $\left(\mathrm{mm}^{3}\right)$ & $24,390(4229)$ & $22,628(2823)$ & 0.79 & 0.0423 \\
Lat ventricle $\left(\mathrm{mm}^{3}\right)$ & $2927(2054)$ & $2771(3944)$ & 5.67 & 0.8365 \\
Cerebellum $\left(\mathrm{mm}^{3}\right)$ & $28,227(4050)$ & $26,893(3156)$ & 4.96 & 0.5868 \\
\hline
\end{tabular}

Hem, Hemispheric; Subcort, subcortical; GM, gray matter; umWM, unmyelinated white matter; Lat; lateral; M, male; F, female; NA, not applicable.

${ }^{a}$ Paired $t$ test.

(Table 3). The magnitude of the asymmetry was more pronounced in the female brain in both regions, with significant gender differences in asymmetries in the prefrontal $\left(t_{(72)}=2.2 ; p=0.0272\right)$ and occipital $\left(t_{(72)}=-2.3 ; p=0.0243\right)$ regions.

\section{Discussion}

The early postnatal period is characterized by a robust growth of cortical gray matter compared with white matter, as well as by a posterior to anterior regional specificity of cortical gray matter growth. Sexual dimorphisms are generally similar to those found in later stages of brain development, indicating that adult patterns of sexual dimorphism arise before birth and persist throughout postnatal brain development. The patterns of cerebral asymmetry in this period of brain development are different from those observed in older children and adults, suggesting that adult patterns of cerebral asymmetry arise after birth.

Overall brain volume in the neonatal period is $\sim 35 \%$ that of normal adults scanned on the same scanner (Mortamet et al., 2005), indicating that there is enormous overall growth of the brain between birth and adulthood. Early results from follow-up scans at 1 year of age suggest that total brain size increases $100 \%$ in the first year of life to $\sim 73 \%$ of adult size (our unpublished results).

In the first weeks after birth, there is a robust increase in cortical gray matter volumes, likely the result of exuberant development of new synapses in the cortex, which has been observed in human and nonhuman primates (Huttenlocher, 1979; Bourgeois and Rakic, 1993; Bourgeois et al., 1994; Huttenlocher and Dabholkar, 1997). Interestingly, there is regional specificity to this gray matter growth, with occipital and parietal regions growing significantly more than prefrontal regions. This pattern suggests that gray matter is maturing faster in the sensory and motor regions than in the prefrontal regions, reflecting the rapid maturation of visual and motor functions relative to the executive functions of the prefrontal cortex in the early postnatal period (Kagen and Herschkowitz, 2005). This pattern of gray matter development is also consistent with a similar posterior to anterior maturation of cortical white matter tracts, with the occipital poles myelinating before the frontotemporal poles (Sampaio and Truwit, 2001).

The regional differences in gray matter growth is consistent with previous studies of synapse development in the human brain, in which synapse numbers peak at 3-4 months in the occipital cortex and at 4-5 years in the prefrontal cortex (Huttenlocher and Dabholkar, 1997). In nonhuman primates, there does not appear to be regional differences in synapse development (Bourgeois and Rakic, 1993; Bourgeois et al., 1994), and whether there are real regional differences in humans has been debated (Rakic et al., 1994). Although overall volume gray matter changes are an indirect measure of synapse proliferation, our results are supportive of regional differences in synapse development in humans.

Sexual dimorphism is present in the neonatal brain. After birth, males have $\sim 9 \%$ larger ICVs than females. This difference in ICV is similar to that observed in adults, $11.9-14.6 \%$ (Gur et al., 1999; Raz et al., 2004). Infant males had 10\% more cortical gray matter than females, which is similar to the $10-11 \%$ differences in gray matter observed in older children (Reiss et al., 1996; Giedd et al., 1999) and the 7-10\% differences noted in adults (Gur et al., 1999; Allen et al., 2003). Males also had 6\% more cortical white matter, similar to the $7.5 \%$ differences in older children (Reiss et al., 1996) but less than the 17-15\% differences found in adults (Gur et al., 1999; Allen et al., 2003). Sexual dimorphism in head circumference has been observed as early as the second trimester in human and nonhuman primates on ultrasound (Joffe et al., 2005). Our study suggests that adult patterns of sexual dimorphisms of overall ICV and cortical gray matter volume are present at birth, whereas adult patterns of 
cortical white matter and lateral ventricle volumes develop after birth.

The left hemisphere-greater than-right hemisphere asymmetry present after birth is the opposite of the right-greater than-left asymmetry observed in older children and adults (Caviness et al., 1996; Giedd et al., 1996; Nopoulos et al., 2000; Good et al., 2001; Matsuzawa et al., 2001; Raz et al., 2004). The magnitude of cerebral asymmetries in the early postnatal period is also greater than the asymmetries observed in older children and adults, which are modest (Reiss et al., 1996; Gur et al., 1999; Matsuzawa et al., 2001). For example, although we found a 5\% left-greater thanright difference in hemispheric gray matter in the neonatal brain, Gur et al. (1999) found a 0.19\% right-greater than-left difference in adults. There was a significant asymmetry in cortical white matter in our cohort, whereas white matter volumes are symmetric in adults (Gur et al., 1999).

Adult patterns of overall fronto-occipital asymmetry or torque are not present in the neonate. Although we did find the expected right-greater than-left asymmetry in the occipital region, the expected prefrontal region asymmetries are not present. Prefrontal asymmetry appears to develop after birth, and this lack of asymmetry may reflect a relative "immaturity" of the prefrontal regions compared with occipital regions, consistent with the slower trajectory of prefrontal gray matter growth pattern versus posterior cortical regions. Interestingly, the magnitude of asymmetry in each region was significantly larger in females, in contrast to studies in adults that found no gender difference in the magnitude of torque (Raz et al., 2004).

Cerebral asymmetries are present at birth in humans, indicating they arise during prenatal brain development. A previous ultrasound study found that this left-greater than-right hemisphere asymmetry is present as early as 20-22 weeks gestational age (Hering-Hanit et al., 2001). Left-greater than-right asymmetry of the lateral ventricles has also been observed in the fetus using ultrasound (Achiron et al., 1997). In a postmortem study of fetal and neonatal tissue, the right frontal region was found to be larger than the left, whereas the left occipital region was larger than the right (Weinberger et al., 1982). This contrasts with our finding that the left prefrontal region is the same volume or even larger than the right.

Asymmetry patterns present in the neonatal brain are likely attributable to genetic programs that operate during prenatal brain development, because gene expression in the human embryonic cortex is asymmetric as early as 12 weeks (Sun et al., 2005; Sun and Walsh, 2006). Adult patterns of asymmetry are also likely the result of genetic programming and environmental influences on postnatal brain development. A recent study of cerebral asymmetry in 14-year-old children who were born very preterm found normal fronto-occipital asymmetry, suggesting that environmental insults to the developing brain at this very early age does not affect adult asymmetry patterns (Lancefield et al., 2006). Children with post-traumatic stress disorder have a loss of normal frontal lobe asymmetry, suggesting that postnatal stress may influence development of adult patterns of asymmetry (Carrion et al., 2001).

Although the automatic segmentation approach used is the best available for reproducible, highly automated segmentation with good validity given the processing needs of a study with a large number of subjects, there are a few limitations to this approach. There appears to be a slight overestimation of the region of early white matter myelination, especially in the region of the lower anterior part of the internal capsule. Binary classification (i.e., tissue label maps) may misclassify tissue in regions that do not exhibit a clear assignment to gray or white matter. This problem will be addressed in future studies by calculating regional tissue volumes through integration of tissue probability values, produced by the currently applied EMS instead of hard labels. Such a procedure might also better cope with partial voluming at the very thin cortical gray matter layer, which in label color maps leaves the impression of overestimation of gray matter.

The current parcellation is based on a Talairach-based box parcellation of the brain volume with separation of subcortical regions, brain stem, and cerebellum. Our results provide information about overall regional growth in the cortex but does not provide detailed information about specific lobes or subregions within the cortex. Growth trajectories of cortical lobes, such as those defined in the semiautomated approach of Nishida et al. (2006), may differ from the results presented in this study, but the overall pattern of posterior-greater than-anterior growth should be consistent.

In summary, brain development in the first weeks of life is characterized by rapid cortical gray matter growth that is regionally specific. Overall, sexual dimorphism of brain size at this age is similar to that found in older children and adults, although there are some subtle differences in patterns of cerebral gray and white matter volumes. The pattern of cerebral asymmetry in neonates is opposite to that of older children and adults and suggests that adult patterns of cerebral asymmetry are the result of ongoing neurodevelopmental processes active after birth, driven by genetic programming as well by experience. There is much to learn about human brain development in the first years of life. We are currently following this cohort with longitudinal imaging and developmental assessments at ages 1 and 2 years.

\section{References}

Achiron R, Yagel S, Rotstein Z, Inbar O, Mashiach S, Lipitz S (1997) Cerebral lateral ventricular asymmetry: is this a normal ultrasonographic finding in the fetal brain? Obstet Gynecol 89:233-237.

Allen JS, Damasio H, Grabowski TJ, Bruss J, Zhang W (2003) Sexual dimorphism and asymmetries in the gray-white composition of the human cerebrum. NeuroImage 18:880-894.

Bilder RM, Wu H, Bogerts B, Degreef G, Ashtari M, Alvir JM, Snyder PJ, Lieberman JA (1994) Absence of regional hemispheric volume asymmetries in first-episode schizophrenia. Am J Psychiatry 151:1437-1447.

Bourgeois JP, Rakic P (1993) Changes of synaptic density in the primary visual cortex of the macaque monkey from fetal to adult stage. J Neurosci 13:2801-2820.

Bourgeois JP, Goldman-Rakic PS, Rakic P (1994) Synaptogenesis in the prefrontal cortex of rhesus monkeys. Cereb Cortex 4:78-96.

Carrion VG, Weems CF, Eliez S, Patwardhan A, Brown W, Ray RD, Reiss AL (2001) Attenuation of frontal asymmetry in pediatric posttraumatic stress disorder. Biol Psych 50:943-951.

Caviness Jr VS, Kennedy DN, Richelme C, Rademacher J, Filipek PA (1996) The human brain age 7-11 years: a volumetric analysis based on magnetic resonance images. Cereb Cortex 6:726-736.

Courchesne E, Chisum HJ, Townsend J, Cowles A, Covington J, Egaas B, Harwood M, Hinds S, Press GA (2000) Normal brain development and aging: quantitative analysis at in vivo MR imaging in healthy volunteers. Radiology 216:672-682.

De Bellis MD, Keshavan MS, Beers SR, Hall J, Frustaci K, Masalehdan A, Noll J, Boring AM (2001) Sex differences in brain maturation during childhood and adolescence. Cereb Cortex 11:552-557.

Evans AC, Collins DL, Mills SR, Brown ED, Kelly RL, Peters TM (1993) 3D statistical neuroanatomical models from 305 MRI volumes. Proc IEEE Nucl Sci Symp Med Imaging Conf 3:1813-1817.

Foundas AL, Corey DM, Angeles V, Bollich AM, Crabtree-Hartman E, Heilman KM (2003) Atypical cerebral laterality in adults with persistent developmental stuttering. Neurology 61:1378-1385.

Giedd JN, Snell JW, Lange N, Rajapakse JC, Casey BJ, Kozuch PL, Vaituzis AC, Vauss YC, Hamburger SD, Kaysen D, Rapoport JL (1996) Quanti- 
tative magnetic resonance imaging of human brain development: ages 4-18. Cereb Cortex 6:551-560.

Giedd JN, Blumenthal J, Jeffries NO, Castellanos FX, Liu H, Zijdenbos A, Paus T, Evans AC, Rapoport JL (1999) Brain development during childhood and adolescence: a longitudinal MRI study. Nat Neurosci 2:861-863.

Gilmore JH, Zhai G, Wilber K, Smith JK, Lin W, Gerig G (2004) 3 Tesla magnetic resonance imaging of the brain in newborns. Psychiatry Res 132:81-85.

Goldstein JM, Seidman LJ, Horton NJ, Makris N, Kennedy DN, Caviness Jr VS, Faraone SV, Tsuang MT (2001) Normal sexual dimorphism of the adult human brain assessed by in vivo magnetic resonance imaging. Cereb Cortex 11:490-497.

Goldstein JM, Seidman LJ, O’Brien LM, Horton NJ, Kennedy DN, Makris N, Caviness Jr VS, Faraone SV, Tsuang MT (2002) Impact of normal sexual dimorphisms on sex differences in structural brain abnormalities in schizophrenia assessed by magnetic resonance imaging. Arch Gen Psychiatry 59:154-164.

Good CD, Johnsrude I, Ashburner J, Henson RN, Friston KJ, Frackowiak RS (2001) Cerebral asymmetry and the effects of sex and handedness on brain structure: a voxel-based morphometric analysis of 465 normal adult human brains. NeuroImage 14:685-700.

Gur RC, Turetsky BI, Matsui M, Yan M, Bilker W, Hughett P, Gur RE (1999) Sex differences in brain gray and white matter in healthy young adults: correlations with cognitive performance. J Neurosci 19:4065-4072.

Hazlett HC, Poe M, Gerig G, Smith RG, Provenzale J, Ross A, Gilmore J, Piven J (2005) Magnetic resonance imaging and head circumference study of brain size in autism: birth through age 2 years. Arch Gen Psychiatry 62:1366-1376.

Herbert MR, Ziegler DA, Deutsch CK, O'Brien LM, Kennedy DN, Filipek PA, Bakardjiev AI, Hodgson J, Takeoka M, Makris N, Caviness Jr VS (2005) Brain asymmetries in autism and developmental language disorder: a nested whole-brain analysis. Brain 128:213-226.

Hering-Hanit R, Achiron R, Lipitz S, Achiron A (2001) Asymmetry of fetal cerebral hemispheres: in utero ultrasound study. Arch Dis Child Fetal Neonatal Ed 85:F194-F196.

Honea R, Crow TJ, Passingham D, Mackay CE (2005) Regional deficits in brain volume in schizophrenia: a meta-analysis of voxel-based morphometry studies. Am J Psychiatry 162:2233-2245.

Hong KE, Ock SM, Kang MH, Kim CE, Bae JN, Lim MK, Suh CH, Chung SJ, Cho SC, Lee JS (2002) The segmented regional volumes of the cerebrum and cerebellum in boys with Tourette syndrome. J Korean Med Sci 17:530-536.

Huppi PS, Warfield S, Kikinis R, Barnes PD, Zientara GP, Jolesz FA, Tsuji MK, Volpe JJ (1998) Quantitative magnetic resonance imaging of brain development in premature and mature newborns. Ann Neurol 43:224-235.

Huttenlocher PR (1979) Synaptic density in human frontal cortex - developmental changes and effects of aging. Brain Res 163:195-205.

Huttenlocher PR, Dabholkar AS (1997) Regional differences in synaptogenesis in human cerebral cortex. J Comp Neurol 387:167-178.

Joffe TH, Tarantal AF, Rice K, Leland M, Oerke AK, Rodeck C, Geary M, Hindmarsh P, Wells JC, Aiello LC (2005) Fetal and infant head circumference sexual dimorphism in primates. Am J Phys Anthropol 126:97-110

Kagen J, Herschkowitz N (2005) A young mind in a growing brain. Mahwah, NJ: Erlbaum.

Lancefield K, Nosarti C, Rifkin L, Allin M, Sham P, Murray R (2006) Cerebral asymmetry in 14 year olds born very preterm. Brain Res 1093:33-40.

Looney CB, Smith JK, Merck LH, Wolfe HM, Chescheir NC, Hamer RM, Gilmore JH (2007) Intracranial hemorrhage in asymptomatic neonates: prevalence on MR scans and relationship to obstetric and neonatal risk factors. Radiology 242:535-541.

Matsuzawa J, Matsui M, Konishi T, Noguchi K, Gur RC, Bilker W, Miyawaki
T (2001) Age-related volumetric changes of brain gray and white matter in healthy infants and children. Cereb Cortex 11:335-342.

Mortamet B, Donglin Z, Gerig G, Prastawa M, Bullitt E (2005) Effects of healthy aging measured by intracranial compartment volumes using designed MR brain database. Med Image Comput Comput Assist Interv Int Conf Med Image Comput Comput Assist Interv 8:383-391.

Nishida M, Makris N, Kennedy DN, Vangel M, Fischl B, Krishnamoorthy KS, Caviness VS, Grant PE (2006) Detailed semi-automated MRI results based on morphometry of the neonatal brain: preliminary results. NeuroImage 32:1041-1049.

Nopoulos P, Flaum M, O’Leary D, Andreasen NC (2000) Sexual dimorphism in the human brain: evaluation of tissue volume, tissue composition and surface anatomy using magnetic resonance imaging. Psychiatry Res 98:1-13.

Peterson BS, Anderson AW, Ehrenkranz R, Staib LH, Tageldin M, Colson E, Gore JC, Duncan CC, Makuch R, Ment LR (2003) Regional brain volumes and their later neurodevelopmental correlates in term and preterm infants. Pediatrics 111:939-948.

Pfefferbaum A, Mathalon DH, Sullivan EV, Rawles JM, Zipursky RB, Lim KO (1994) A quantitative magnetic resonance imaging study of changes in brain morphology from infancy to late adulthood. Arch Neurol 51:874-887.

Prastawa M, Gilmore JH, Lin W, Gerig G (2005) Automatic segmentation of MR images of the developing newborn brain. Med Image Anal 9:457-466.

Rakic P, Bourgeois JP, Goldman-Rakic PS (1994) Synaptic development of the cerebral cortex: implications for learning, memory, and mental illness. Prog Brain Res 102:227-243.

Raz N, Gunning-Dixon F, Head D, Rodrigue KM, Williamson A, Acker JD (2004) Aging, sexual dimorphism, and hemispheric asymmetry of the cerebral cortex: replicability of regional differences in volume. Neurobiol Aging 25:377-396.

Reiss AL, Abrams MT, Singer HS, Ross JL, Denckla MB (1996) Brain development, gender and IQ in children. A volumetric imaging study. Brain 119:1763-1774

Rojas DC, Camou SL, Reite ML, Rogers SJ (2005) Planum temporale volume in children and adolescents with autism. J Autism Dev Disord 35:479-486.

Rueckert D, Sonoda LI, Hayes C, Hill DL, Leach MO, Hawkes DJ (1999) Nonrigid registration using free-form deformations: application to breast MR images. IEEE Trans Med Imaging 18:712-721.

Sampaio RC, Truwit CL (2001) Myelination in the developing brain. In: Handbook of developmental cognitive neuroscience (Nelson CA, Luciana $\mathrm{M}$, eds), pp 35-44. Cambridge, MA: MIT.

Sommer I, Ramsey N, Kahn R, Aleman A, Bouma A (2001) Handedness, language lateralisation and anatomical asymmetry in schizophrenia: meta-analysis. Br J Psychiatry 178:344-351.

Sun T, Walsh CA (2006) Molecular approaches to brain asymmetry and handedness. Nat Rev Neurosci 7:655-662.

Sun T, Patoine C, bu-Khalil A, Visvader J, Sum E, Cherry TJ, Orkin SH, Geschwind DH, Walsh CA (2005) Early asymmetry of gene transcription in embryonic human left and right cerebral cortex. Science 308:1794-1798.

Toga AW, Thompson PM (2003) Mapping brain asymmetry. Nat Rev Neurosci 4:37-48.

Van Leemput K, Maes F, Vandermeulen D, Suetens P (1999) Automated model-based tissue classification of MR images of the brain. IEEE Trans Med Imaging 18:897-908.

Warfield SK, Kaus M, Jolesz FA, Kikinis R (2000) Adaptive, template moderated, spatially varying statistical classification. Med Image Anal 4:43-55.

Weinberger DR, Luchins DJ, Morihisa J, Wyatt RJ (1982) Asymmetrical volumes of the right and left frontal and occipital regions of the human brain. Ann Neurol 11:97-100.

Wells WM, Grimson WEL, Kikinis R, Jolesz FA (1996) Adaptive segmentation of MRI Data. IEEE Trans Med Imaging 15:429-443. 